\title{
Updated investigations of cancer excesses in individuals born or resident in the vicinity of Sellafield and Dounreay
}

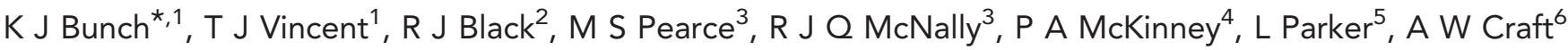 \\ and M F G Murphy ${ }^{1}$
}

${ }^{1}$ Childhood Cancer Research Group, New Richards Building, University of Oxford, Old Road Campus, Headington, Oxford OX3 7LG, UK; ${ }^{2}$ Information Services Division, NHS National Services Scotland, 1 South Gyle Crescent, Edinburgh EH12 9EB, UK; ${ }^{3}$ Institute of Health and Society, Newcastle University, Sir James Spence Institute, Royal Victoria Infirmary, Queen Victoria Road, Newcastle upon Tyne NE1 4LP, UK; ${ }^{4}$ Division of Epidemiology and Biostatistics, University of Leeds, 8.49 Worsley Building, Leeds LS2 9JT, UK; ${ }^{5}$ Dalhousie University, IWK Health Centre, 5850/5980 University Avenue, Halifax, Nova Scotia B3K 6R8, Canada and ${ }^{6}$ Northern Institute for Cancer Research, Paul O'Gorman Building, Medical School, Newcastle University, Framlington Place, Newcastle upon Tyne NE2 4HH, UK

Background: Earlier studies have shown raised risks of leukaemia and non-Hodgkin lymphoma in children, teenagers and young adults resident either at birth or diagnosis in Seascale. Some increases in cancer risk in these age groups have also been noted among those living around Dounreay. We aimed to update previous analyses relating to areas close to these nuclear installations by considering data from an additional 16 years of follow-up.

Methods: Cross-sectional analyses compared cancer incidence rates for 1963-2006 among those aged 0-24 years at diagnosis living in geographically specified areas around either Sellafield or Dounreay with general population rates. Cancer incidence for the period 1971-2006 among the cohort of Cumbrian births between 1950 and 2006 was compared to national incidence for 1971-2006 using person-years analysis. Cancer among those born in the postcode sector closest to Dounreay was compared with that among those born in the three adjoining postcode sectors. Analyses considered both cancer overall and ICD-O-3 defined diagnostic subgroups including leukaemia, central nervous system tumours and other malignancies.

Results: Apart from previously reported raised risks, no new significantly increased risks for cancer overall or any diagnostic subgroup were found among children or teenagers and young adults living around either nuclear installation. Individuals born close to the installations from 1950 to 2006 were not shown to be at any increased risk of cancer during the period 1971 to date.

Conclusions: Analysis of recent data suggests that children, teenagers and young adults currently living close to Sellafield and Dounreay are not at an increased risk of developing cancer. Equally, there is no evidence of any increased cancer risk later in life among those resident in these areas at birth.

Previous studies have investigated claims of excesses of leukaemia and other cancers not only among children, but also among teenagers and young adults (aged 0-14 and 15-24 years, respectively) in the vicinity of nuclear installations generally and, within Great Britain, around Sellafield and Dounreay specifically.
In particular, an increased risk of lymphoid leukaemia and non-Hodgkin lymphoma (NHL) was reported among children, teenagers and young adults living in Seascale during 1963-1990 (Draper et al, 1993). A raised risk of leukaemia was found among the same age group living within $12.5 \mathrm{~km}$ of Dounreay during the

*Correspondence: KJ Bunch; E-mail: kathryn.bunch@retired.ox.ac.uk

Received 23 December 2013; revised 16 May 2014; accepted 4 June 2014; published online 22 July 2014

(c) 2014 Cancer Research UK. All rights reserved 0007-0920/14 
period 1979-1984 (Heasman et al, 1986). A subsequent study (Sharp et al, 1996) reported an excess of childhood leukaemia and NHL within $25 \mathrm{~km}$ of Dounreay for the period 1968-1993. Although Draper and colleagues noted suggestions of a possible increased risk for other tumour types among teenagers and young adults (aged 15-24 years) resident around Sellafield, no corresponding increased risk has been reported among those living around Dounreay.

A more recent British study (Bithell et al, 2013) considered leukaemia incidence in children aged under 5 living in the vicinity of nuclear power plants and found little evidence of an increased risk in contrast to findings from Germany (Kaatsch et al, 2008). In France, a possible increased risk for acute childhood leukaemia was observed among children living $<5 \mathrm{~km}$ from a nuclear power plant for the period 2002-2007 (Sermage-Faure et al, 2012). This raised risk was not evident in the previous decade or among children living at any greater distance from the plants.

An excess cancer mortality risk among children and young adults was observed in the population born in Seascale between 1950 and 1983 (Gardner et al, 1987). The increased follow-up now available allows investigation of whether the excess cancer risks continue beyond the ages considered by Gardner. Although a similar birth cohort study found no significantly raised risk for children born around the Dounreay site (Black et al, 1992), further investigation of cancer risk beyond age 20 for these individuals is also warranted for comparison.

Studies of cancer incidence relating to these two nuclear installations have been evaluated by the Committee on Medical Aspects of Radiation in the Environment (COMARE) and COMARE reports have included recommendations about future monitoring. COMARE's 11th report (Committee on Medical Aspects of Radiation in the Environment (COMARE), 2006) recommended that the incidence of childhood leukaemia and other cancers was kept under periodic review in the areas surrounding both Sellafield and Dounreay as the reported excesses appeared real, if unexplained, and were unlikely to be due to chance (COMARE 10th report (Committee on Medical Aspects of Radiation in the Environment (COMARE), 2005)). COMARE 11 also suggested that it was appropriate to investigate whether the cancer excess occurs in age groups older than 25 years of age.

In the analyses described here, we evaluate the cancer incidence during childhood and young adulthood among those individuals resident during 1991-2006 around either Sellafield or Dounreay nuclear installations and compare it with that for earlier periods. Also, by contrast, we estimate the cancer risk, at any age, among those individuals born between 1950 and 2006, while resident close to either installation, irrespective of their subsequent place of residence within Great Britain.

\section{MATERIALS AND METHODS}

Cancer excesses in the vicinities of Sellafield and Dounreay were investigated separately but using methods for each as similar as the availability of cancer incidence and population data around the two distinct locations allowed. Briefly, standardised incidence ratios (SIRs) were calculated for cross-sectional populations and also for birth cohorts, applying national cancer registration rates for the same years to the calculated populations at risk to derive expected numbers for comparison with the numbers of events observed.

Analyses relating to Sellafield. Three designated areas within Cumbria for which both population and cancer registration data were available were defined (Figure 1):

1. Seascale ward (as defined at the time of the 1981 census)

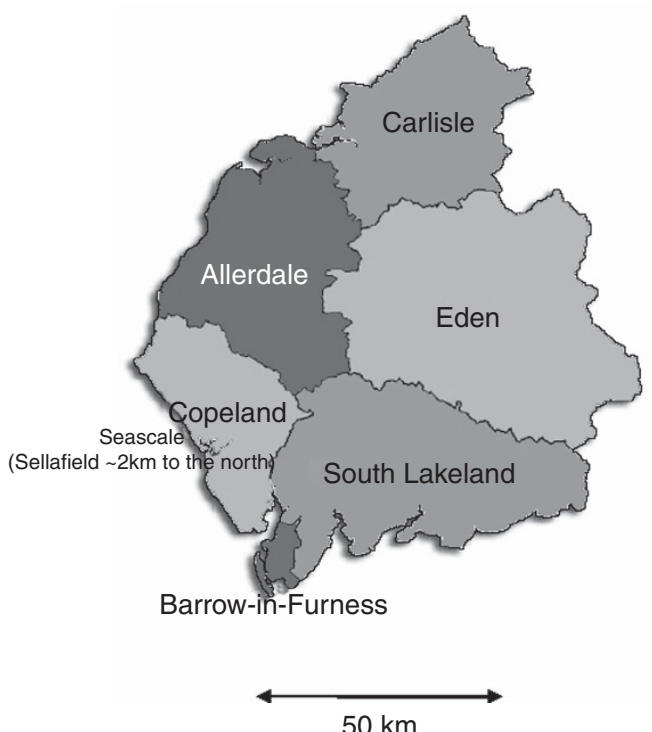

Figure 1. The county districts of Cumbria.

2. The county districts (CDs) of Allerdale and Copeland excluding Seascale ward

3. The remainder of Cumbria, that is, the CDs of Carlisle, Eden, South Lakeland and Barrow-in-Furness

At the 2001 census, the geographical area of Seascale ward increased substantially; so only those output areas corresponding to the old Seascale ward boundaries were included as Seascale.

For cross-sectional analyses of cancer among 15 to 24-year olds, Barrow-in-Furness was excluded because the Northern Region Young Persons' Malignant Disease Registry (NRYPMDR) did not collect data from this area.

Cross-sectional analysis. Census data were used to derive agespecific population estimates for the three areas around Sellafield described above. Table 1 shows the mean number of children (aged $0-14$ ) and teenagers and young adults (aged 15-24) resident in each of these three areas over the three time periods to be considered. National Registry of Childhood Tumours (NRCT) data were then used to determine the number of childhood cancers occurring to residents of each area in any given time period. These resulting rates were compared with NRCT national rates for England, Wales and Scotland (EWS) for the corresponding time period. Similarly, cancers in teenagers and young adults in Cumbria were identified from the NRYPMDR and the rates were compared to corresponding rates for the remainder of the NRYPMDR area.

Birth cohort analysis. In summary, a cohort was assembled to include all individuals born in Cumbria between 1950 and 2006 to mothers resident in Cumbria at the time of the child's birth. Cohort members were then assigned to one of the same three designated areas on the basis of the postcode of their mother's usual address at the time of the child's birth.

A pre-existing cohort of children born in Cumbria between 1950 and 1993 (held both at the Office for National Statistics (ONS) and by collaborators at Newcastle University) formed the starting point of the cohort for our analyses. The original 19501993 birth cohort formed the database for a programme of work focusing on cancer and adverse birth outcomes in relation to factors such as paternal preconceptional irradiation (Parker et al, 1993, 1999; Dickinson and Parker, 2002) and population mixing (Dickinson and Parker, 1999) as well as a range of geographical 
Table 1. Summary of average annual population estimates for study areas

Around Sellafield

\begin{tabular}{|l|c|c|c|c|c|c|}
\hline & \multicolumn{2}{|c|}{ Seascale ward } & Copeland and Allerdale minus Seascale & \multicolumn{2}{c}{ Rest of Cumbria } \\
\hline Period & $0-14$ years & $15-24$ years & $0-14$ years & $15-24$ years & $0-14$ years & $15-24$ years \\
\hline $1963-1983^{\mathbf{a}}$ & 533 & 294 & 38571 & 24398 & 67649 & 33225 \\
\hline $1984-1990$ & 343 & 267 & 30880 & 24805 & 56529 & 36890 \\
\hline $1991-2006$ & 299 & 160 & 29763 & 18463 & 56702 & 27856 \\
\hline $1963-2006$ & 418 & 232 & 34144 & 21974 & 61899 & 31639 \\
\hline
\end{tabular}

Around Dounreay

\begin{tabular}{|l|c|c|c|}
\hline & \multicolumn{2}{|c|}{ Thurso and Reay civil parishes } & \multicolumn{2}{c|}{ Remaining civil parishes of Caithness } \\
\hline Period & $0-14$ years & $15-24$ years & $14-24$ years \\
\hline $1963-1983$ & 2817 & 1586 & 4297 \\
\hline $1984-1990$ & 2067 & 1590 & 3606 \\
\hline $1991-2006$ & 1747 & 1193 & 3188 \\
\hline $1963-2006$ & 2309 & 1444 & 3784 \\
\hline
\end{tabular}

a 1969-1983 for 15-24 age group as cancer incidence data are only available from 1969

${ }^{b_{\text {Rest }}}$ of Cumbria excludes Barrow-in-Furness county district for the 15-24 age group.

information system-based studies in relation to the areas around Sellafield (Dummer et al, 1998).

To complete the cohort, ONS identified those children born between 1994 and 2006 to mothers resident in Cumbria. Data relating to members of the Cumbria Birth Cohort, both the pre-existing Cumbrian cohort of children born 1950-1993 $(n=278665)$ and the extension to the cohort, born 1994-2006 $(n=64430)$, were supplied from the National Health Service Information Centre (NHSIC).

NHSIC were unable to supply birth address information for the 1950-1993 part of the cohort so, to enable identification of individuals born in the geographical areas of interest it was necessary to match the NHSIC version of the cohort with that held at Newcastle University, which included the necessary address information. No completely consistent identifiers linked the two versions of the cohort, making this a complex matching exercise, but $98.5 \%$ of the records in the NHSIC version of the cohort, taken as the definitive version for this study, were matched to records from the Newcastle version.

The birth cohort was flagged at ONS and researchers were notified of all deaths, cancer diagnoses (after 1971) or emigrations (and thus losses to follow-up) among cohort members provided the individual was still alive in 1991 when records were transferred to the Central Health Register Inquiry System (CHRIS). The General Register Office for Scotland likewise provided notifications for members of the cohort who had migrated to Scotland. These returns were used to calculate incidence rates, for both childhood and adult cancers for the period 1971-2006, which have been compared with corresponding population rates.

It became apparent that the Cumbria cohort as supplied by NHSIC was missing those individuals born in Cumbria from 1950 to 1991 who had died before the introduction of CHRIS. Similarly, there were no cancers recorded pre-1991 unless the individual survived beyond 1991.

Newcastle agreed to allow access to the data they hold on deaths and cancers pre-1991. However, the cancer information they hold (ascertained in the 1990s) may not be complete and in some cases the coding and diagnosis date recorded were not consistent with those supplied by NHSIC. To complete the cohort we added 7788 individuals from the Newcastle version of the cohort identified as having died before 1991 and a further 3123 individuals identified as having embarked before 1991. Newcastle had identified 356 cancer diagnoses among the 7788 individuals who had died prior to 1991. To obtain consistent cancer information for cohort members we asked NHSIC to check those individuals against the ONS cancer records and this information was incorporated into the analyses. Scrutiny of the additional cases included in the cohort suggested that their inclusion does not bias the findings of the study in any way.

Careful cross checking between the ONS and Newcastle versions of the pre-1994 cohort meant that cohort members who died or emigrated before 1991 were able to be included in the study and any cancers recorded for these individuals between 1971 and 1991 are included in the analyses that follow.

\section{Analyses relating to Dounreay}

Cross-sectional analysis. Two geographical areas surrounding the Dounreay nuclear installation have been defined for which population estimates for the relevant age groups are publicly available and within which cancer cases can be identified. The area closest to Dounreay consists of the civil parishes of Thurso and Reay (Figure 2), while the second area consists of the remaining civil parishes of Caithness, geographically a very much larger area but with a relatively sparse population. Table 1 shows the average annual population of children (0-14 years) and teenagers and young adults (15-24 years) for both areas for each of the three time periods under consideration.

Childhood cancers (aged 0-14) occurring in each area were identified from the NRCT. Cancers in teenagers and young adults (aged 15-24) were identified from records held by the Information Services Division (ISD) in Scotland. Rates for children were compared with the corresponding NRCT rates for EWS for the equivalent time periods. Rates for teenagers and young adults were compared with cancer registrations for Scotland for the same age group and time periods. 

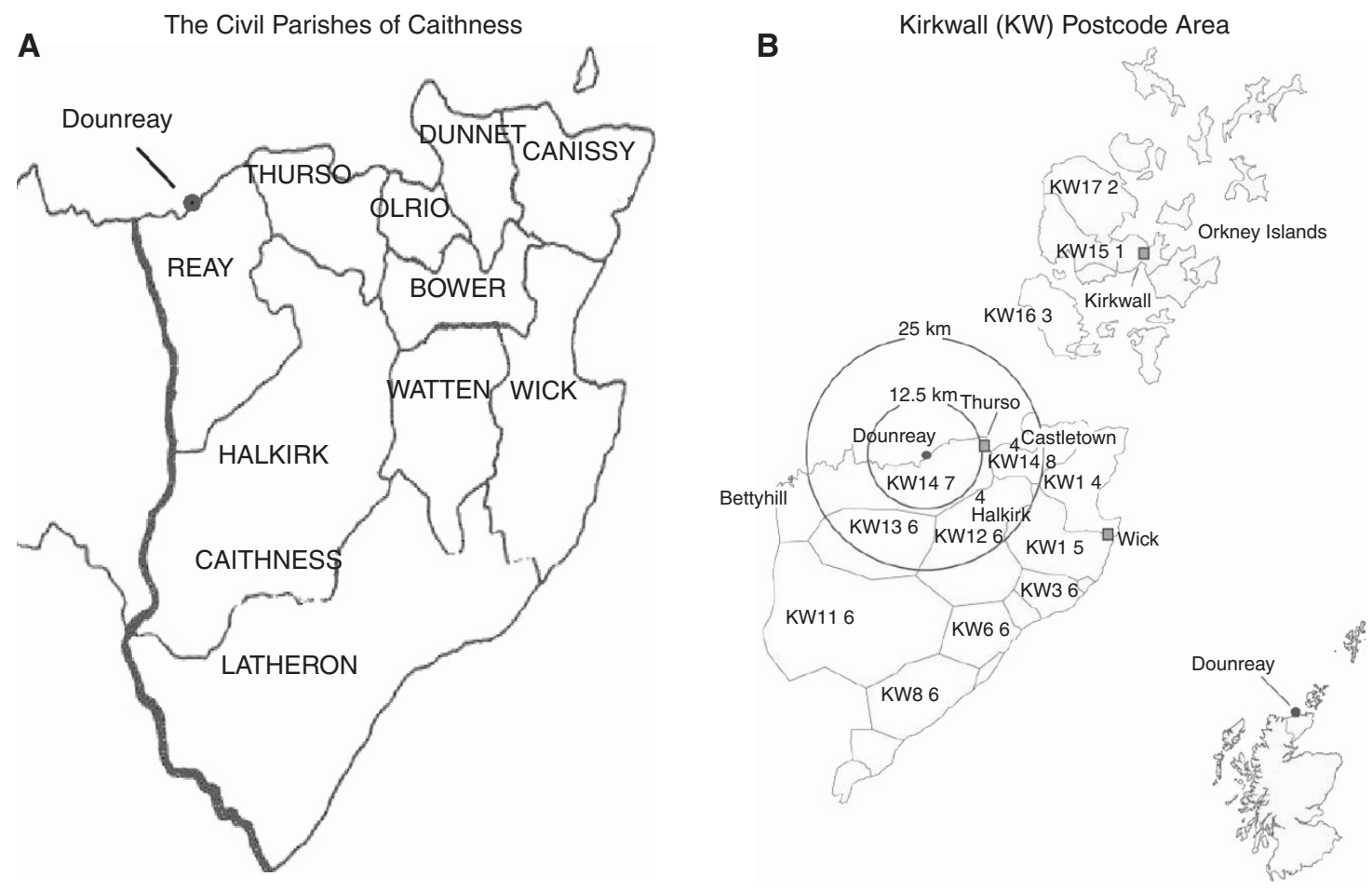

Figure 2. (A) The civil parishes of Caithness. (B) Kirkwall (KW) postcode area.

Birth cohort analysis. Children born between 1950 and 2006 in two specified areas around Dounreay (Figure 2) were identified:

1. Postcode sector KW14 7

2. Postcode sectors KW12 6, KW13 6 and KW14 8

The cohort birth records were linked to cancer registrations held by ISD to obtain information on malignancies among cohort members.

The information on cancer diagnoses among Dounreay cohort members was restricted to cancers in those still alive at the introduction of Community Health Index (CHI) numbers in Scotland. As it was not possible to obtain any national estimate of cancer incidence on a similar ascertainment basis, time from study entry (birth) to study exit (cancer diagnosis or 31 December 2006) was compared for those born in the two defined study areas instead.

Outcome measures. Throughout the analyses included in this study, cancer incidence is the outcome measure under consideration.

The cross-sectional analyses concentrate on cancers among children (aged 0-14 years) and teenagers and young adults (aged 15-24 years). The cohort analyses consider cancer incidence occurring between 1971 and 2006 at any age with the earliest born cohort members approaching age 57 at the close of the study in 2006. For both types of analyses, total cancer is defined to include all malignant tumours (except non-melanoma skin cancers) together with all central nervous system or brain tumours of uncertain or benign nature. Age appropriate diagnostic subgroups, categorised by the International Classification of Diseases for Oncology, Third Edition (ICD-O-3; World Health Organisation, 2000) were considered for each type of analysis as shown in Table 2.

The Cumbria cohort analyses were performed using STATA, Version 11 statistical software (StataCorp., 2009, College Station, TX, USA) and report SIRs together with corresponding 95\% confidence intervals (CIs). Using the same software, Log-rank tests
Table 2. Diagnostic subgroups considered in cross-sectional and cohort analyses

\begin{tabular}{|l|l|}
\hline $\begin{array}{l}\text { Cross-sectional analyses } \\
\text { (diagnoses at ages } \mathbf{0 - 2 4 )}\end{array}$ & $\begin{array}{l}\text { Cohort analyses } \\
\text { (diagnoses at ages 0-57) }\end{array}$ \\
\hline Total cancer & Total cancer \\
\hline Total leukaemia & Total leukaemia \\
\hline Lymphoid leukaemia & Non-Hodgkin lymphoma \\
\hline Other leukaemia & Hodgkin lymphoma \\
\hline Total leukaemia and non-Hodgkin lymphoma & Brain and CNS tumours \\
\hline Non-Hodgkin lymphoma & Melanoma of the skin \\
\hline Hodgkin lymphoma & Neuroblastoma and ganglioneuroblastoma \\
\hline Brain and CNS tumours & Upper respiratory tract tumours \\
\hline Other solid tumours & Gastrointestinal tract tumours \\
\hline & Lower respiratory tract tumours \\
\hline & Breast cancer \\
\hline & Genitourinary tract tumours \\
\hline & Thyroid cancer \\
\hline Abbreviation: CNS=central nervous system. & \\
\hline & \\
\hline
\end{tabular}

were used to compare cancer incidence among individuals born in the two specified areas around Dounreay.

\section{RESULTS}

Seascale

Cross-sectional analysis. Numbers of leukaemias, other cancers and total cancer cases identified among residents in Seascale Ward (as defined for the 1981 census), Copeland and Allerdale CDs and the rest of Cumbria are shown in Table 3 together with SIRs and 
Table 3. Numbers of observed and expected cases and SIRs for individuals aged 0-14 and 15-24 resident around Sellafield

Ages $0-14$ years

Ages 15-24 years

\begin{tabular}{|c|c|c|c|c|c|c|c|c|}
\hline & Cases & Expected & $S I^{a}$ & $95 \% \mathrm{Cl}$ & Cases & Expected & $\operatorname{SIR}^{\mathrm{b}}$ & $95 \% \mathrm{Cl}$ \\
\hline \multicolumn{9}{|c|}{ Seascale ward } \\
\hline \multicolumn{9}{|c|}{ Total leukaemia } \\
\hline $1963-1983^{c}$ & 4 & 0.41 & 9.85 & $2.68-25.22$ & 0 & 0.09 & 0.00 & $0.00-34.44$ \\
\hline 1984-1990 & 1 & 0.10 & 10.28 & $0.26-57.26$ & 0 & 0.04 & 0.00 & $0.00-71.99$ \\
\hline 1991-2006 & 0 & 0.21 & 0.00 & $0.00-14.07$ & 1 & 0.05 & 18.56 & $0.46-103.38$ \\
\hline 1963-2006 & 5 & 0.73 & $\underline{6.85}$ & $2.22-15.96$ & 1 & 0.18 & 5.47 & $0.14-30.47$ \\
\hline \multicolumn{9}{|c|}{ Other tumours } \\
\hline $1963-1983^{c}$ & 1 & 0.81 & 1.24 & $0.03-6.90$ & 0 & 0.57 & 0.00 & $0.00-5.23$ \\
\hline 1984-1990 & 1 & 0.20 & 4.95 & $0.13-27.59$ & 3 & 0.28 & 10.61 & $2.19-31.02$ \\
\hline 1991-2006 & 1 & 0.46 & 2.19 & $0.06-12.21$ & 0 & 0.38 & 0.00 & $0.00-7.85$ \\
\hline 1963-2006 & 3 & 1.50 & 1.99 & $0.41-5.83$ & 3 & 1.25 & 2.40 & $0.50-7.03$ \\
\hline \multicolumn{9}{|c|}{ All malignancies } \\
\hline $1963-1983^{c}$ & 5 & 1.21 & 4.12 & $1.33-9.60$ & 0 & 0.66 & 0.00 & $0.00-4.54$ \\
\hline 1984-1990 & 2 & 0.30 & 6.68 & $0.81-24.11$ & 3 & 0.32 & 9.25 & $1.91-27.01$ \\
\hline 1991-2006 & 1 & 0.67 & 1.49 & $0.04-8.30$ & 1 & 0.44 & 2.30 & $0.06-12.81$ \\
\hline 1963-2006 & 8 & 2.23 & 3.58 & $1.54-7.05$ & 4 & 1.43 & 2.80 & $0.76-7.17$ \\
\hline
\end{tabular}

\section{Copeland and Allerdale county districts (excluding Seascale ward)}

Total leukaemia

\begin{tabular}{|c|c|c|c|c|c|c|c|c|}
\hline $1963-1983^{c}$ & 22 & 29.37 & 0.75 & $0.47-1.13$ & 9 & 6.98 & 1.29 & $0.59-2.45$ \\
\hline 1984-1990 & 10 & 8.76 & 1.14 & $0.55-2.10$ & 2 & 3.46 & 0.58 & $0.07-2.08$ \\
\hline 1991-2006 & 19 & 21.17 & 0.90 & $0.69-1.40$ & 6 & 6.19 & 0.97 & $0.36-2.11$ \\
\hline $1963-2006$ & 51 & 59.61 & 0.86 & $0.64-1.13$ & 17 & 16.72 & 1.02 & $0.59-1.63$ \\
\hline \multicolumn{9}{|l|}{ Other tumours } \\
\hline $1963-1983^{c}$ & 56 & 58.36 & 0.96 & $0.73-1.25$ & 55 & 49.96 & 1.10 & $0.83-1.43$ \\
\hline 1984-1990 & 18 & 18.18 & 0.99 & $0.59-1.57$ & 30 & 27.51 & 1.09 & $0.74-1.56$ \\
\hline 1991-2006 & 46 & 45.39 & 1.01 & $0.74-1.35$ & 48 & 45.44 & 1.06 & $0.78-1.40$ \\
\hline 1963-2006 & 120 & 122.84 & 0.98 & $0.81-1.17$ & 133 & 123.10 & 1.08 & $0.91-1.28$ \\
\hline \multicolumn{9}{|c|}{ All malignancies } \\
\hline $1963-1983^{c}$ & 78 & 87.73 & 0.89 & $0.71-1.11$ & 64 & 56.94 & 1.12 & $0.87-1.45$ \\
\hline 1984-1990 & 28 & 26.93 & 1.04 & $0.69-1.51$ & 32 & 30.97 & 1.03 & $0.71-1.46$ \\
\hline 1991-2006 & 65 & 66.56 & 0.98 & $0.76-1.26$ & 54 & 51.63 & 1.05 & $0.79-1.37$ \\
\hline 1963-2006 & 171 & 182.45 & 0.94 & $0.80-1.09$ & 150 & 139.82 & 1.07 & $0.91-1.26$ \\
\hline
\end{tabular}

\section{Remainder of Cumbriad}

Total leukaemia

\begin{tabular}{|c|c|c|c|c|c|c|c|c|}
\hline $1963-1983^{c}$ & 52 & 51.50 & 1.01 & $0.76-1.33$ & 6 & 9.57 & 0.63 & $0.23-1.37$ \\
\hline 1984-1990 & 25 & 16.03 & 1.56 & $1.01-2.31$ & 3 & 5.27 & 0.57 & $0.12-1.66$ \\
\hline 1991-2006 & 37 & 40.33 & 0.92 & $0.65-1.27$ & 5 & 9.34 & 0.54 & $0.17-1.25$ \\
\hline 1963-2006 & 114 & 108.07 & 1.05 & $0.87-1.27$ & 14 & 24.19 & 0.58 & $0.32-0.97$ \\
\hline \multicolumn{9}{|l|}{ Other tumours } \\
\hline $1963-1983^{c}$ & 102 & 102.36 & 1.00 & $0.81-1.21$ & 63 & 67.43 & 0.93 & $0.72-1.20$ \\
\hline 1984-1990 & 30 & 33.27 & 0.90 & $0.61-1.29$ & 35 & 40.54 & 0.86 & $0.60-1.20$ \\
\hline 1991-2006 & 73 & 86.48 & 0.84 & $0.66-1.06$ & 59 & 68.52 & 0.86 & $0.66-1.11$ \\
\hline 1963-2006 & 205 & 222.70 & 0.92 & $0.80-1.06$ & 157 & 176.23 & 0.89 & $0.76-1.04$ \\
\hline \multicolumn{9}{|l|}{ All malignancies } \\
\hline $1963-1983^{c}$ & 154 & 153.861 & 1.00 & $0.85-1.18$ & 69 & 77.01 & 0.90 & $0.70-1.14$ \\
\hline 1984-1990 & 55 & 49.304 & 1.12 & $0.84-1.46$ & 38 & 45.81 & 0.83 & $0.59-1.14$ \\
\hline 1991-2006 & 110 & 126.808 & 0.87 & $0.72-1.05$ & 64 & 77.86 & 0.82 & $0.64-1.06$ \\
\hline 1963-2006 & 319 & 330.763 & 0.96 & $0.86-1.08$ & 171 & 200.42 & 0.85 & $0.73-0.99$ \\
\hline
\end{tabular}

Abbreviations: $\mathrm{CD}=$ county district; $\mathrm{Cl}=$ confidence interval; $\mathrm{EWS}=$ England, Wales and Scotland; NRCT=National Registry of Childhood Tumours; NRYPMDR = Northern Region Young Persons' Malignant Disease Registry; SIRs = standardised incidence ratios. SIRs which differ significantly from 1 are shown in bold $(P<0.05)$, bold and underlined $(P<0.01)$.

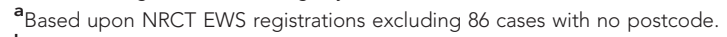

b Based upon registrations from the Northern Region Young Persons Malignant Disease Registry excluding those for Cumbria.

c1969-1983 for 15-24 age group as NRYPMDR data are only available from 1969.

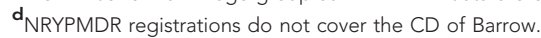


95\% CIs. Supplementary Tables S1a, S1b and S1c give further detail of the numbers of tumours and SIRs by diagnostic subgroup.

The top panel of Table 3 shows a single case of childhood cancer (shown in other malignancies in Supplementary Table S1a) together with a single leukaemia among teenagers and young adults during the period 1991-2006 among those resident in Seascale ward. Our re-analysis of the data confirms the significantly raised incidence of leukaemia among children between 1963 and 1983 (SIR 9.85, 95\% CI 2.68-25.22) and the raised incidence of non-leukaemia tumours among teenagers and young adults between 1984 and 1990 (SIR 10.61, 2.19-31.02).

The second panel of Table 3 shows the number of cancers and SIRs for the area surrounding Seascale ward-Allerdale and Copeland CDs (excluding Seascale ward). Corresponding information for the remainder of Cumbria is shown in the third panel. There are no suggestions of significantly raised incidence of cancer in children, teenagers and young adults in Allerdale and Copeland CDs during any of the periods covered by this study. Historically, it has been the practice to consider leukaemia and NHL together because of inconsistencies in diagnoses. In the remainder of Cumbria, when these two subgroups were combined (see Supplementary Table S1c) there was a significant excess of cases among children aged 0-14 during the period 1984-1990 (SIR 1.64, 1.11-2.33), but this excess was not evident in either the earlier or later periods studied. Teenagers and young adults (aged 15-24) appeared to be at a non-significantly reduced risk for leukaemia in each of the time periods studied and when the time periods were combined, this reduced risk became significant (SIR 0.58, $0.32-0.97)$. Driven by this reduced leukaemia risk, overall cancer risk in teenagers and young adults was again non-significantly reduced in each of the three separate time periods and significantly reduced when the time periods were combined (SIR 0.85, 0.73-0.99).
Birth cohort analysis. Data relating to the entire Cumbrian Birth Cohort, both the earlier part based on the pre-existing Cumbrian cohort of children born during 1950-1993 $(n=278665)$ and its extension, those born during 1994-2006 $(n=64430)$, were supplied from the NHSIC. Overall, 1379 individuals were identified as having been born within Seascale ward, 122980 within Allerdale and Copeland CDs and 213760 within the remainder of Cumbria, contributing 37989.4, 3192368 and 5369045.7 person-years, respectively to the analyses that follow.

Table 4 shows SIRs for cancer overall and each of the 12 diagnostic subgroups listed in Table 2 for each of the three designated study areas. There is no indication of any significant excesses either of cancer overall or any individual diagnostic subgroup of tumours among those born in Seascale ward or Cumbria more generally. Further analyses were undertaken stratifying by sex, age group at diagnosis, birth decade and diagnosis decade (results for cancer overall are shown in Supplementary Table S2). For cancer overall, the reduced cancer risk in both areas of Cumbria outside of Seascale was greater in males than females, but otherwise no important variations across the strata were evident.

\section{Dounreay}

Cross-sectional analysis. Numbers of cancer cases and, separately, leukaemia and other tumours, SIRs and 95\% CIs at ages 0-14 and 15-24 diagnosed in the civil parishes of Thurso and Reay and, separately, the remaining civil parishes of Caithness are shown in Table 5. For childhood cancers the national comparative rates were derived from NRCT registrations for EWS, whereas for the teenage and young adult cancers (aged 15-24) comparative rates were based on Scottish cancer incidence rates (from ISD).

\begin{tabular}{|c|c|c|c|c|c|c|c|c|c|c|c|c|c|c|c|}
\hline \multirow[b]{3}{*}{ Total cancer } & \multicolumn{5}{|c|}{ Seascale ward as at 1981} & \multicolumn{5}{|c|}{$\begin{array}{l}\text { Allerdale and Copeland CDs } \\
\text { excluding Seascale }\end{array}$} & \multicolumn{5}{|c|}{ Remainder of Cumbria } \\
\hline & \multirow{2}{*}{\begin{tabular}{|c|}
$\begin{array}{l}\text { Tumours } \\
\text { observed }\end{array}$ \\
21
\end{tabular}} & \multirow{2}{*}{\begin{tabular}{|c|}
$\begin{array}{l}\text { Tumours } \\
\text { expected }\end{array}$ \\
22.35 \\
\end{tabular}} & \multirow{2}{*}{\begin{tabular}{|l|} 
SIR \\
0.94
\end{tabular}} & \multicolumn{2}{|c|}{$95 \% \mathrm{Cl}^{\mathrm{a}}$} & \multirow{2}{*}{\begin{tabular}{|c|}
$\begin{array}{c}\text { Tumours } \\
\text { observed }\end{array}$ \\
1573
\end{tabular}} & \multirow{2}{*}{\begin{tabular}{|c|}
$\begin{array}{c}\text { Tumours } \\
\text { expected }\end{array}$ \\
1796.63 \\
\end{tabular}} & \multirow{2}{*}{\begin{tabular}{|l|} 
SIR \\
$\underline{\underline{0.88}}$ \\
\end{tabular}} & \multicolumn{2}{|c|}{$95 \% \mathrm{Cl}^{\mathrm{a}}$} & \multirow{2}{*}{\begin{tabular}{|c|}
$\begin{array}{c}\text { Tumours } \\
\text { observed }\end{array}$ \\
2637
\end{tabular}} & \multirow{2}{*}{\begin{tabular}{|c|}
$\begin{array}{c}\text { Tumours } \\
\text { expected }\end{array}$ \\
2901.73 \\
\end{tabular}} & \multirow{2}{*}{\begin{tabular}{|l|} 
SIR \\
0.91 \\
\end{tabular}} & \multicolumn{2}{|c|}{$95 \% \mathrm{Cl}^{\mathrm{a}}$} \\
\hline & & & & 0.58 & 1.44 & & & & 0.83 & 0.92 & & & & 0.87 & 0.94 \\
\hline Leukaemia & 2 & 1.2 & 1.67 & 0.2 & 6.03 & 81 & 102.96 & $\overline{0.79}$ & 0.63 & 0.98 & 151 & 174.57 & $\overline{0.86}$ & 0.73 & 1.01 \\
\hline $\begin{array}{l}\text { Non-Hodgkin } \\
\text { lymphoma }\end{array}$ & 2 & 1.28 & 1.57 & 0.19 & 5.66 & 80 & 101.42 & 0.79 & 0.63 & 0.98 & 133 & 164.07 & 0.81 & 0.68 & 0.96 \\
\hline Hodgkin disease & 2 & 0.91 & 2.19 & 0.27 & 7.91 & 71 & 73.05 & 0.97 & 0.76 & 1.23 & 107 & 120.51 & 0.89 & 0.73 & 1.07 \\
\hline CNS/brain tumours & 0 & 1.71 & 0.00 & 0.00 & 1.75 & 122 & 140.65 & 0.87 & 0.72 & 1.04 & 237 & 232.99 & 1.02 & 0.89 & 1.16 \\
\hline Melanoma of the skin & 1 & 1.58 & 0.63 & 0.02 & 3.53 & 109 & 124.29 & 0.88 & 0.72 & 1.06 & 200 & 201.32 & 0.99 & 0.86 & 1.14 \\
\hline $\begin{array}{l}\text { Neuroblastoma and } \\
\text { ganglioneuroblastoma }\end{array}$ & 0 & 0.08 & 0.00 & 0.00 & 35.41 & 9 & 8.36 & 1.08 & 0.49 & 0.05 & 15 & 15.07 & 1.00 & 0.56 & 1.64 \\
\hline $\begin{array}{l}\text { Mouth, oropharynx, } \\
\text { larynx and URT } \\
\text { tumours }\end{array}$ & 1 & 0.73 & 1.37 & 0.04 & 7.61 & 52 & 57.79 & 0.90 & 0.67 & 1.18 & 95 & 91.90 & 1.03 & 0.84 & 1.26 \\
\hline GI tract tumours & 1 & 1.35 & 0.74 & 0.02 & 4.11 & 83 & 106.37 & 0.78 & 0.62 & 0.97 & 146 & 167.67 & 0.87 & 0.74 & 1.02 \\
\hline $\begin{array}{l}\text { Lung, trachea and LRT } \\
\text { tumours }\end{array}$ & 0 & 0.92 & 0.00 & 0.00 & 3.25 & 76 & 73.61 & 1.03 & 0.81 & 1.29 & 103 & 115.90 & 0.89 & 0.73 & 1.08 \\
\hline Breast tumours & 7 & 5.18 & 1.35 & 0.54 & 2.78 & 382 & 413.00 & 0.92 & 0.84 & 1.02 & 576 & 656.99 & 0.88 & 0.81 & 0.95 \\
\hline GU tumours & 3 & 4.81 & 0.62 & 0.13 & 1.82 & 321 & 381.96 & 0.84 & 0.75 & 0.94 & 562 & 615.97 & 0.91 & 0.84 & 0.99 \\
\hline Thyroid cancer & 0 & 0.44 & 0.00 & 0.00 & 6.88 & 30 & 34.74 & 0.86 & 0.58 & 1.23 & 59 & 56.85 & 1.04 & 0.79 & 1.34 \\
\hline
\end{tabular}


Supplementary Tables S3a and S3b show details of cancer incidence and risk by diagnostic subgroup.

Table 5 shows no excess of childhood cancer among 0 to 14 -year olds or 15 to 24 -year olds resident in Thurso and Reay during the period 1991-2006. During this period, there were two cases of cancer among 0 to 14 -year olds and five cases of cancer among 15 to 24-year olds, none of which were leukaemias. For cancer overall, the SIR for the period was 0.51 (95\% CI 0.06-1.84) for the 0 to 14 -year age group and $0.95(0.31-2.21)$ for the 15 to 24 -year age group.

For the remaining civil parishes of Caithness there were six cases of childhood cancer during the period 1991-2006 and four cases of cancer among 15 to 24-year olds. None of the individual SIRs for this period were significantly raised (or reduced) and for cancer overall, the SIR was $0.84(0.31-1.83)$ for 0 to 14 -year olds and 0.46 (0.13-1.18) for 15 to 24-year olds.

None of the cancer cases diagnosed between 1991 and 2006 in either age group or in either area were leukaemia.
Birth cohort analysis. The cohort identified by ISD included 8091 individuals of which 3932 had been born in the area closest to Dounreay (postcode sector KW14 7) and 4159 in the three surrounding postcode sectors.

Information Services Division supplied 93 notifications of a malignant tumour (excluding non-melanoma skin tumours) or a non-malignant brain tumour relating to members of the cohort; 42 of these tumours (2 leukaemias) arose in individuals born in the area closest to Dounreay and the remaining 51 (7 leukaemias) in individuals born in the area further from Dounreay.

Table 6 shows the cumulative cancer incidence since birth for those born in each of the two study areas. Log-rank tests $(P=0.99)$ confirmed that there is no difference between the overall cancer incidence of these two subgroups within the cohort. Where there were sufficient numbers (five or more cases), incidence for the diagnostic groups detailed in Table 2 was compared between these two subgroups (data not shown) and no differences were found.

Table 5. Numbers of observed and expected cases and SIRs for individuals aged 0-14 and 15-24 resident around Dounreay during 1963-2006

\begin{tabular}{|c|c|c|c|c|c|c|c|c|}
\hline & \multicolumn{4}{|c|}{ Ages $0-14$ years } & \multicolumn{4}{|c|}{ Ages $15-24$ years } \\
\hline & Cases & Expected & $\operatorname{SIR}^{\mathrm{a}}$ & $95 \% \mathrm{Cl}$ & Cases & Expected & $S I R^{b}$ & $95 \% \mathrm{Cl}$ \\
\hline \multicolumn{9}{|c|}{ Thurso and Reay civil parishes } \\
\hline \multicolumn{9}{|c|}{ Total leukaemia } \\
\hline 1963-1983 & 5 & 2.14 & 2.33 & $0.75-5.43$ & 0 & 0.65 & 0.00 & $0.00-4.60$ \\
\hline 1984-1990 & 1 & 0.59 & 1.71 & $0.04-9.52$ & 2 & 0.22 & 9.22 & $1.12-33.28$ \\
\hline $1991-2006$ & 0 & 1.24 & 0.00 & $0.00-2.41$ & 0 & 0.55 & 0.00 & $0.00-5.46$ \\
\hline 1963-2006 & 6 & 4.03 & 1.49 & $0.55-3.25$ & 2 & 1.43 & 1.40 & $0.17-5.05$ \\
\hline \multicolumn{9}{|l|}{ Other tumours } \\
\hline $1963-1983$ & 2 & 4.26 & 0.47 & $0.06-1.70$ & 4 & 5.26 & 0.76 & $0.21-1.95$ \\
\hline 1984-1990 & 0 & 1.22 & 0.00 & $0.00-2.46$ & 3 & 2.18 & 1.37 & $0.28-4.02$ \\
\hline $1991-2006$ & 2 & 2.66 & 0.75 & $0.09-2.71$ & 5 & 4.71 & 1.06 & $0.34-2.48$ \\
\hline 1963-2006 & 4 & 8.31 & 0.48 & $0.13-1.23$ & 12 & 12.26 & 0.98 & $0.51-1.71$ \\
\hline \multicolumn{9}{|c|}{ All malignancies } \\
\hline 1963-1983 & 7 & 6.41 & 1.09 & $0.44-2.25$ & 4 & 5.91 & 0.68 & $0.18-1.74$ \\
\hline 1984-1990 & 1 & 1.80 & 0.55 & $0.01-3.06$ & 5 & 2.40 & 2.08 & $0.67-4.85$ \\
\hline $1991-2006$ & 2 & 3.91 & 0.51 & $0.06-1.84$ & 5 & 5.26 & 0.95 & $0.31-2.21$ \\
\hline $1963-2006$ & 10 & 12.34 & 0.81 & $0.39-1.49$ & 14 & 13.69 & 1.02 & $0.56-1.71$ \\
\hline \multicolumn{9}{|c|}{ Remaining civil parishes of Caithness } \\
\hline \multicolumn{9}{|c|}{ Total leukaemia } \\
\hline 1963-1983 & 5 & 3.27 & 1.53 & $0.50-3.56$ & 0 & 1.02 & 0.00 & $0.00-2.95$ \\
\hline 1984-1990 & 3 & 1.02 & 2.93 & $0.60-8.56$ & 0 & 0.34 & 0.00 & $0.00-8.85$ \\
\hline $1991-2006$ & 0 & 2.27 & 0.00 & $0.00-1.32$ & 0 & 0.91 & 0.00 & $0.00-3.31$ \\
\hline $1963-2006$ & 8 & 6.61 & 1.21 & $0.52-2.38$ & 0 & 2.27 & 0.00 & $0.00-1.32$ \\
\hline \multicolumn{9}{|l|}{ Other tumours } \\
\hline $1963-1983$ & 5 & 6.50 & 0.77 & $0.25-1.80$ & 5 & 8.22 & 0.61 & $0.20-1.42$ \\
\hline $1984-1990$ & 1 & 2.12 & 0.47 & $0.01-2.63$ & 3 & 3.41 & 0.88 & $0.18-2.57$ \\
\hline $1991-2006$ & 6 & 4.86 & 1.23 & $0.45-2.69$ & 4 & 7.77 & 0.51 & $0.14-1.32$ \\
\hline $1963-2006$ & 12 & 13.61 & 0.88 & $0.46-1.54$ & 12 & 19.48 & 0.62 & $0.32-1.08$ \\
\hline \multicolumn{9}{|c|}{ All malignancies } \\
\hline 1963-1983 & 10 & 9.77 & 1.02 & $0.49-1.88$ & 5 & 9.24 & 0.54 & $0.17-1.26$ \\
\hline $1984-1990$ & 4 & 3.15 & 1.27 & $0.35-3.25$ & 3 & 3.75 & 0.80 & $0.16-2.34$ \\
\hline $1991-2006$ & 6 & 7.13 & 0.84 & $0.31-1.83$ & 4 & 8.68 & 0.46 & $0.13-1.18$ \\
\hline $1963-2006$ & 20 & 20.22 & 0.99 & $0.60-1.52$ & 12 & 21.74 & 0.55 & $0.28-0.96$ \\
\hline \multicolumn{9}{|c|}{ 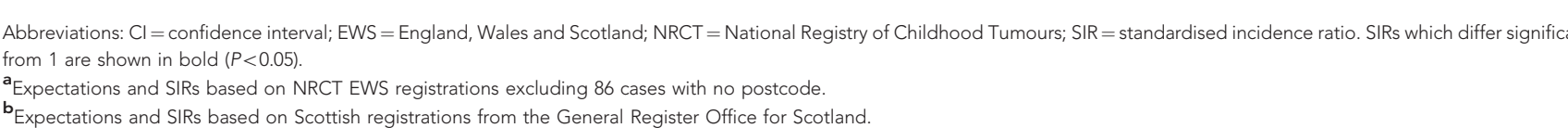 } \\
\hline
\end{tabular}




\begin{tabular}{|c|c|c|c|c|c|}
\hline By age & $\begin{array}{l}\text { No. of } \\
\text { persons } \\
\text { at risk }\end{array}$ & $\begin{array}{c}\text { Cumulative } \\
\text { no. of } \\
\text { cancers }\end{array}$ & $\begin{array}{l}\% \text { no } \\
\text { cancer }\end{array}$ & $95 \%$ & $\mathrm{Cl}$ \\
\hline \multicolumn{6}{|c|}{ Individuals resident at birth in postcode sector KW14 7} \\
\hline 5 & 3656 & 2 & 99.95 & 99.79 & 99.99 \\
\hline 10 & 3370 & 2 & 99.95 & 99.79 & 99.99 \\
\hline 15 & 3063 & 3 & 99.92 & 99.74 & 99.97 \\
\hline 25 & 2238 & 12 & 99.57 & 99.24 & 99.76 \\
\hline 35 & 1496 & 23 & 98.95 & 98.40 & 99.31 \\
\hline 45 & 513 & 34 & 97.86 & 96.89 & 98.54 \\
\hline 55 & 45 & 42 & 92.71 & 87.03 & 95.96 \\
\hline \multicolumn{6}{|c|}{$\begin{array}{l}\text { Individuals resident at birth in postcode sectors KW12 6, } \\
\text { KW13 } 6 \text { and KW14 } 8\end{array}$} \\
\hline 5 & 3844 & 3 & 99.92 & 99.77 & 99.98 \\
\hline 10 & 3535 & 5 & 99.87 & 99.69 & 99.95 \\
\hline 15 & 3196 & 7 & 99.81 & 99.60 & 99.91 \\
\hline 25 & 2444 & 14 & 99.57 & 99.27 & 99.75 \\
\hline 35 & 1693 & 26 & 99.00 & 98.51 & 99.32 \\
\hline 45 & 688 & 37 & 98.01 & 97.15 & 98.61 \\
\hline 55 & 85 & 51 & 93.26 & 89.39 & 95.75 \\
\hline
\end{tabular}

\section{DISCUSSION}

The results of our cross-sectional analyses indicate that no excesses of childhood and young adult cancer around Sellafield and Dounreay are evident when more recent data covering the period from 1991 to 2006 are considered. Our findings for the earlier time periods (1963-1990) are consistent with earlier published findings (Black et al, 1992; Draper et al, 1993).

Detailed analysis of cancer incidence within the Cumbria birth cohort suggests no increase in risk for the period 1971-2006 either for cancer overall or for any specific diagnostic subgroup among individuals born in Seascale ward or the surroundings areas of Cumbria. This is true both for childhood tumours and, among the earlier born cohort members, for malignancies occurring during adult life. Equally, there is no raised cancer risk evident in those members of the Dounreay cohort born closest to Dounreay as compared to those cohort members born further away from the nuclear installation. However, it must be noted that many of the results reported are based on small numbers and must therefore be treated with appropriate caution.

In recent years, there has been considerable interest in cancer incidence around nuclear installations among children aged 0-4 years whereas the results of the cross-sectional analyses we present relate to childhood cancer as a whole (0-14 years). However, closer inspection of the data, especially that for the newly reported period 1991-2006, did not reveal any excesses among the younger children that were not already present in the broader age group.

Previous studies of cancer incidence around nuclear installations have focused on leukaemia, particularly in those studies relating to children and young adults. The third COMARE report (Committee on Medical Aspects of Radiation in the Environment (COMARE), 1989), however, noted a raised risk of non-leukaemia tumours around nuclear establishments in Berkshire and therefore, as recommended by COMARE, we report on the incidence of brain and other solid tumours in addition to leukaemia. In terms of the cohort studies, which predominately examine cancer incidence in adults, we examined all major diagnostic groupings rather than restricting the analysis to the tumour groups most prevalent in childhood.

Explanations for the changing pattern of cancer risk observed among children and teenagers and young adults around Sellafield and Dounreay can only be speculative. Variation in environmental factors over time may have resulted in time-related changes in exposure. Evidence linking radioactive discharges to cancer incidence is slim but there has been a reduction over time in radioactive discharges from these two installations. Discharges from Sellafield are certainly lower in more recent years (Hunt, 1995; Environment Agency, Food Standards Agency, Northern Ireland Environment Agency, Scottish Environment Protection Agency, 2013). However it has previously been suggested (Committee on Medical Aspects of Radiation in the Environment (COMARE), 1988, 1996; Muirhead, 1998; Wakeford, 2003; Wakeford, 2013) that, for both installations, discharges were always too small to have explained the observed leukaemia excesses. A major review of epidemiological studies of leukaemia in children and young adults around nuclear facilities (Laurier et al, 2008) concluded that while local excesses, including those previously reported around Sellafield and Dounreay, were apparent, none of the multi-site studies showed an increased risk of leukaemia overall in these age groups. Thus, while our results show a change in risk pattern over time around these two particular installations, the absence of an excess risk for a particular time period is not unique.

A major re-examination of cancer risk around nuclear installations in the United States includes an appraisal of study design and methodology (Wing et al, 2011). A single complete, population-based cancer registration system and hence the ability to use cancer incidence rather than cancer mortality data are two of the issues problematic to US studies that our study circumvents. However, the cost and effort involved in obtaining individual exposure data integrated over time from conception to diagnosis, as highlighted by Wing et al, raises corresponding difficulties for any UK study.

Other kinds of exposure to ionising radiation from naturally occurring sources are unlikely to account for the clusters and trends since natural exposure levels are thought stable over time (Kendall et al, 2013). Similarly, although intrauterine growth patterns are thought to influence childhood cancer rates (O'Neill et al, 2012), there is no reason to believe that the general increase in average birthweight or proportion of babies with high birthweight, could account for a localised cluster and subsequent decline in rates. Again, despite the evidence that some childhood cancers are genetically influenced (Stiller, 2004), population genetic changes in the areas around Sellafield and Dounreay are very unlikely to account for the changing patterns of cancer incidence observed over the study period.

Other analyses, examining cancer incidence in children living close to overhead powerlines (Bunch et al, 2014) have found a similar pattern of raised risks evident in earlier decades (Draper et al, 2005) reducing over a similar time span. Clearly, while any hypothesised mechanisms underlying the raised risks initially observed in these two studies will be different, it is nevertheless of interest to observe a similar pattern of risk reduction over a period of some 50 years.

A leading alternative hypothesis to account for the increases in childhood leukaemia observed previously around nuclear installations involves levels of unusual population mixing. Childhood cancer, in particular leukaemia, may be a rare response to as yet unidentified infectious agent(s) and an increased rate of population mixing, bringing together infective and susceptible individuals, resulting in outbreaks of infection with rare leukaemogenic consequences (Kinlen, 1988, 1995, 2012). More specifically, a study based on a subset of the Cumbria cohort (Dickinson and Parker, 1999) concluded that population mixing during gestation 
or early in life could account for the increased risk observed around Sellafield. Although we have no exact measure for levels of population mixing, or an appropriate proxy measure, for more recent years, it is reasonable to conclude that population mixing will have reduced over time as the nuclear installation at Sellafield has not expanded greatly in more recent years. The absence of any increased risk of childhood cancer in the more recent data analysed here thus would tend to support the argument for population mixing being a contributory cause of observed clusters and perhaps even suggest that 25-30 years is the time required for the effect of such population mixing to disappear.

All the data for our analyses were taken from pre-existing registers routinely collecting data from geographical areas wider than but including the specific areas in this analysis. Our investigation thus avoided the need to contact individuals and many of the biases associated with reported data in epidemiological studies.

Although we have described some of the difficulties encountered in assembling and monitoring the cohorts, we maintain that, given the inconsistency of recording and registration systems over the long period of this study, our data are as complete and accurate as could be expected. To support this claim, as far as childhood tumours within the Cumbrian cohort are concerned, we identified cases of childhood cancer diagnosed between 1971 and 2006 and registered on the NRCT among individuals whose mothers were resident at the time of the child's birth in the three defined study areas and we compared these with the childhood cancer cases identified from the cohort study. This comparison suggested that the number of cases identified from the cohort was around $10 \%$ lower for the diagnosis period 1971-2006 than expected from the NRCT. In general, we would expect the NRCT to contain a more complete record of childhood cancer than would be the case for other sources. Furthermore, some of these 'missing' cases will have been born outside Cumbria (despite the mother being normally residing in Cumbria) and thus were not eligible for inclusion in the original Cumbria cohort. In particular, of the two Seascale Ward cases identified from NRCT records that did not appear in the cohort analysis, one was born outside Cumbria. The other 'missing case' was diagnosed prior to the introduction of CHRIS but NRCT records would nevertheless suggest that the individual is alive. Examination of the Cumbria 'missing cases' by diagnosis year shows a marked increase in the discrepancy between the two data sources for cases diagnosed in 1991 and 1992-the period immediately following the introduction of CHRIS. The issue arising from non-retention of records relating to individuals no longer alive at the time of the introduction of CHRIS for the Cumbrian cohort was mirrored in the Dounreay cohort by issues surrounding the introduction of $\mathrm{CHI}$ numbers.

Information on tumours diagnosed at 15-24 years of age was supplied without names and thus no attempt could be made to cross-check whether any cancers registered at ages 15-24 years were in fact second primary tumours diagnosed in individuals who had been diagnosed with a first primary tumour in childhood. Such an occurrence would however be very rare $(<1 \%)$ and therefore unlikely to have influenced our findings.

Although children are, in the vast majority of cases, living with their families with a clearly defined residential address, teenagers and young adults are far more mobile and it is likely that there is less consistency in their practice of registration for medical services. This may have some effect on the cancer rates recorded in this age group. Seascale, in particular, has been noted as having an unusually high socioeconomic status that may be associated with an increased tendency to make use of more distant educational facilities making them more likely also to register for medical services away from their parental home address. The reduced incidence of cancer overall and leukaemia in particular noted among teenagers and young adults in Carlisle, Eden and South Lakeland CDs may well be indicative of atypically high outward migration rates among this age group. The most notable reduction in incidence is a deficit of observed leukaemia cases among 20 to 24-year olds though the numbers involved are small (four cases observed as against 9.32 expected). This reduction in incidence could be the result of this age group moving from Cumbria to more urban areas to undertake education or seek employment.

Although there are acknowledged inconsistencies in some of the data sources we have used, we maintain that this study makes best use of the available information and gives unbiased results. Analysis of the most recent data suggests that children, teenagers and young adults currently living close to Sellafield and Dounreay are not at an increased risk of developing cancer. Equally, there is no evidence of any increased cancer risk later in life among those resident in these areas at birth.

\section{ACKNOWLEDGEMENTS}

We are grateful to staff at NHSIC for their help in this study and in particular for their efforts to establish the causes of discrepancies within the Cumbrian cohort. In Scotland, David Shelton (NRS) and Lesley Bhatti (ISD Cancer Surveillance Team) were instrumental in providing data for the study and we also thank Katrina Smith (ISD) for her work in assembling the Dounreay birth cohort. Colleagues at Newcastle University helped us well beyond the original remit of the study-without their help the Cumbrian cohort analyses could not have been completed. In addition to those named as authors, we thank Richard Hardy and Katharine Kirton. We would also like to acknowledge generous help from CCRG colleagues and in particular Dr Gerald Draper for advising on the analysis of the Cumbria cohort data and Nicole Diggens for helping with data management. At the time of this study, the Childhood Cancer Research Group was funded by the Department of Health for England and Wales, the Scottish Government and the National Cancer Intelligence Network. Children with Cancer UK also supported the UK NRCT. Childhood cancer epidemiology research at Newcastle University is supported by the North of England Children's Cancer Research Fund. This study was funded by the Department of Health's Radiation Protection Research Programme (RRX 123).

\section{REFERENCES}

Bithell JF, Murphy MFG, Stiller CA, Toumpakari E, Vincent T, Wakeford R (2013) Leukaemia in young children in the vicinity of British nuclear power plants: a case-control study. $\mathrm{Br} J$ Cancer 109(11): 2880-2885.

Black RJ, Urquhart JD, Kendrick SW, Bunch KJ, Warner J, Adams Jones D (1992) Incidence of leukaemia and other cancers in birth and schools cohorts in the Dounreay area. BMJ 304(6839): 1401-1405.

Bunch KJ, Keegan T, Swanson J, Vincent TJ, Murphy MFG (2014) Residential distance at birth from overhead high-voltage powerlines: childhood cancer risk in Britain 1962-2008. Br J Cancer 110(5): 1402-1408.

Committee on Medical Aspects of Radiation in the Environment (COMARE) (1988) Second Report Investigation of the Possible Increased Incidence of Leukaemia in Young People near the Dounreay Nuclear Establishment, Caithness, Scotland. HMSO: London.

Committee on Medical Aspects of Radiation in the Environment (COMARE) (1989) Third Report Report on the Incidence of Childhood Cancer in the West Berkshire and North Hampshire Area, in which are Situated the Atomic Weapons Research Establishment, Aldermaston and the Royal Ordnance Factory, Burghfield. HMSO: London.

Committee on Medical Aspects of Radiation in the Environment (COMARE) (1996) Fourth Report. The Incidence of Cancer and Leukaemia in Young People in the Vicinity of the Sellafield Site, West Cumbria: Further Studies and an Update of the Situation Since the Publication of the Report of the Black Advisory Group in 1984. Department of Health: Wetherby. 
Committee on Medical Aspects of Radiation in the Environment (COMARE) (2005) COMARE 10th Report: the Incidence of Childhood Cancer Around Nuclear Installations in Great Britain. Health Protection Agency: Chilton, Didcot.

Committee on Medical Aspects of Radiation in the Environment (COMARE) (2006) COMARE 11th Report: the Distribution of Childhood Leukaemia and Other Childhood Cancer in Great Britain 1969-1993. Health Protection Agency: Chilton, Didcot.

Dickinson HO, Parker L (1999) Quantifying the effect of population mixing on childhood leukaemia risk: the Seascale cluster. Br J Cancer 81(1): 144-151.

Dickinson HO, Parker L (2002) Leukaemia and non-Hodgkin's lymphoma in children of male Sellafield radiation workers. Int J Cancer 99(3): 437-444.

Draper G, Vincent T, Kroll ME, Swanson J (2005) Childhood cancer in relation to distance from high voltage power lines in England and Wales: a case-control study. BMJ 330(7503): 1290-1294.

Draper GJ, Stiller CA, Cartwright RA, Craft AW, Vincent TJ (1993) Cancer in Cumbria and in the vicinity of the Sellafield nuclear installation, 1963-90. BMJ 306(6870): 89-94.

Dummer TJ, Dickinson HO, Pearce MS, Charlton ME, Smith J, Salotti J, Parker L (1998) Stillbirth rates around the nuclear installation at Sellafield, North West England: 1950-1989. Int J Epidemiol 27(1): 74-82.

Environment Agency, Food Standards Agency, Northern Ireland Environment Agency, Scottish Environment Protection Agency (2013) Radioactivity in Food and the Environment, 2012.

Gardner MJ, Hall AJ, Downes S, Terrell JD (1987) Follow up study of children born to mothers resident in Seascale, West Cumbria (birth cohort). Br Med J (Clin Res Ed) 295(6602): 822-827.

Heasman MA, Kemp IW, Urquhart JD, Black R (1986) Childhood leukaemia in northern Scotland. Lancet 327(8475): 266.

Hunt GJ (1995) Radiation doses to critical groups since the early 1950s due to discharges of liquid radioactive waste from Sellafield. In International Symposium on Environmental Impact of Radioactive Releases. ppIAEASM-339/16IAEA: Vienna.

Kaatsch P, Spix C, Schulze-Rath R, Schmiedel S, Blettner M (2008) Leukaemia in young children living in the vicinity of German nuclear power plants. Int $J$ Cancer 122(4): 721-726.

Kendall GM, Little MP, Wakeford R, Bunch KJ, Miles JCH, Vincent TJ, Meara JR, Murphy MFG (2013) A record-based case-control study of natural background radiation and the incidence of childhood leukaemia and other cancers in Great Britain during 1980-2006. Leukemia 27(1): 3-9.

Kinlen L (1988) Evidence for an infective cause of childhood leukaemia: comparison of a Scottish new town with nuclear reprocessing sites in Britain. Lancet 332(8624): 1323-1327.

Kinlen LJ (1995) Epidemiological evidence for an infective basis in childhood leukaemia. Br J Cancer 71(1): 1-5.
Kinlen LJ (2012) An examination, with a meta-analysis, of studies of childhood leukaemia in relation to population mixing. Br J Cancer 107(7): 1163-1168.

Laurier D, Jacob S, Bernier MO, Leuraud K, Metz C, Samson E, Laloi P (2008) Epidemiological studies of leukaemia in children and young adults around nuclear facilities: a critical review. Radiat Prot Dosimetry 132(2): 182-190.

Muirhead CR (1998) Childhood cancer and nuclear installations: a review. Nucl Energy 37(6): 371-379.

O'Neill KA, Bunch KJ, Murphy MFG (2012) Intrauterine growth and childhood leukemia and lymphoma risk. Expert Rev Hematol 5(5): 559-576.

Parker L, Craft AW, Smith J, Dickinson H, Wakeford R, Binks K, McElvenny D, Scott L, Slovak A (1993) Geographical distribution of preconceptional radiation doses to fathers employed at the Sellafield nuclear installation, West Cumbria. BMJ 307(6910): 966-971.

Parker L, Pearce MS, Dickinson HO, Aitkin M, Craft AW (1999) Stillbirths among offspring of male radiation workers at Sellafield nuclear reprocessing plant. Lancet 354(9188): 1407-1414.

Sermage-Faure C, Laurier D, Goujon-Bellec S, Chartier M, Guyot-Goubin A, Rudant J, Hémon D, Clavel J (2012) Childhood leukemia around French nuclear power plants-the Geocap study, 2002-2007. Int J Cancer 131(5): E769-E780.

Sharp L, Black RJ, Harkness EF, McKinney PA (1996) Incidence of childhood leukaemia and non-Hodgkin's lymphoma in the vicinity of nuclear sites in Scotland, 1968-93. Occup Environ Med 53(12): 823-831.

Stiller CA (2004) Epidemiology and genetics of childhood cancer. Oncogene 23(38): 6429-6444.

Wakeford R (2003) Childhood leukaemia clusters around Sellafield and Dounreay. Nucl Energy 42(4): 213-224.

Wakeford R (2013) The risk of childhood leukaemia following exposure to ionising radiation-a review. J Radiol Prot 33(1): $1-25$.

Wing S, Richardson DB, Hoffmann W (2011) Cancer risks near nuclear facilities: the importance of research design and explicit study hypotheses. Environ Health Perspect 119(4): 417-421.

World Health Organisation (2000) International Classification of Diseases for Oncology, 3rd edn. WHO: Geneva.

This work is published under the standard license to publish agreement. After 12 months the work will become freely available and the license terms will switch to a Creative Commons AttributionNonCommercial-Share Alike 3.0 Unported License.

Supplementary Information accompanies this paper on British Journal of Cancer website (http://www.nature.com/bjc) 